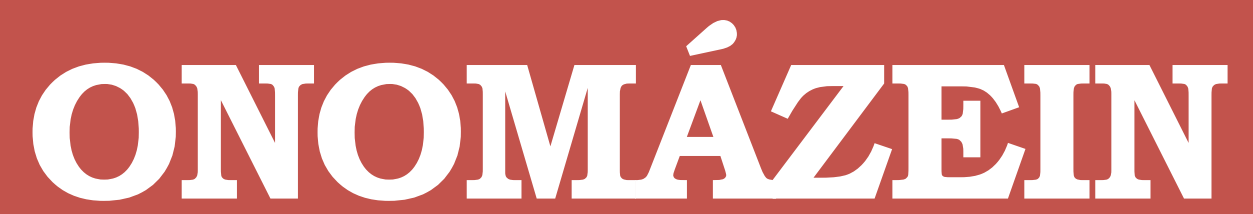

Revista de lingüística, filología y traducción
PONTIFICIA UNIVERSIDAD CATÓLICA DE CHILE FACULTAD DE LETRAS

\title{
Malefactivos y benefactivos. Dos construcciones con dativo de afectación en el español de México ${ }^{1}$
}

Malefactives and benefactives. Two constructions with affected dative in Mexican Spanish

\section{Luis Arturo Díaz García}

Universidad Nacional Autónoma de México

México

\section{Sergio Ibáñez Cerda}

Universidad Nacional Autónoma de México

México

ONOMÁZEIN 45 (septiembre de 2019): 152-187

DOI: 10.7764/onomazein.45.11

ISSN: 0718-5758

\section{(C) $\underset{\mathrm{BY}}{\mathrm{B}} \underset{\mathrm{ND}}{\mathrm{N}}$}

Luis Arturo Díaz García: Posgrado en Lingüística, Universidad Nacional Autónoma de México, México. | Correo electrónico: luisarturo2710@hotmail.com

Sergio Ibáñez Cerda: Centro de Lingüística Hispánica "Juan M. Lope Blanch”, Instituto de Investigaciones Filológicas, Universidad Nacional Autónoma de México, México. | Correo electrónico: cecser@prodigy.net.mx 


\section{Resumen}

En términos tipológicos, se puede diferenciar entre las lenguas que tienen un recurso gramatical específico para marcar a los benefactivos y una forma distinta para los malefactivos, y las lenguas que no diferencian estas categorías con una marca específica. El español normalmente es clasificado entre este último tipo de lenguas (Smith, 2005; Radetzky y Smith, 2010: 99), pues, se arguye, cuenta con una construcción de afectación, la de dativo, que semánticamente activa tanto un efecto positivo como negativo. A partir de un análisis semántico-sintáctico de datos de uso del español de México, este estudio muestra que el dativo de afectación se distribuye en dos tipos de construcciones básicas: las agentivas y las eventivas. En términos de frecuencia, las primeras tienden a manifestar una afectación positiva; las segundas muestran, casi categóricamente, un efecto adverso. Esto indica que en español es posible distinguir dos subcategorías de dativo de afectación: el benefactivo y el malefactivo, y que por lo tanto pertenece, al menos parcialmente, a las lenguas que cuentan con un recurso gramatical diferenciador.

Palabras clave: dativo de afectación; malefactivo; benefactivo; construcciones agentivas; construcciones eventivas.

\section{Abstract}

Languages are distinguished, in typological terms, between those which have a specific grammatical form to mark benefactive participants and a different form to code malefactives, and

1 Las abreviaciones usadas en este artículo son las siguientes:

\begin{tabular}{llllll}
\hline 1 & PRIMERA PERSONA & DAT & DATIVO & PL & PLURAL \\
\hline 2 & SEGUNDA PERSONA & DECL & DECLARATIVO & PRES & PRESENTE \\
\hline 3 & TERCERA PERSONA & IL & ILATIVO & PRET & PRETÉRITO \\
\hline ABL & ABLATIVO & IMP & IMPERATIVO & PTE & PACIENTE \\
\hline AC & ACUSATIVO & MAL & MALEFACTIVO & S & SUJETO \\
\hline AG & AGENTE & NOM & NOMINATIVO & SG & SINGULAR \\
\hline AL & ALATIVO & OD & OBJETO DIRECTO & TOP & TÓPICO \\
\hline APL & APLICATIVO & OP & OBIETO PREPOSITIVO & V & VERBO \\
\hline BEN & BENEFACTIVO & PART & PARTICIPIO & & \\
\hline CL & CLÍTICO & PAS & PASIVO & & \\
\hline
\end{tabular}


those which do not differentiate those categories with specific marks. Spanish is usually classified among this last type of languages (Smith, 2005; Radetzky \& Smith, 2010: 99). It is argued that this language has an affectation construction, the dative one, which can yield a positive effect or, as well, a negative one. In this work, we present a semantic-syntactic analysis based on usage data from Mexican Spanish that shows that the speakers tent, in frequency terms, to use two different constructions for the codification of an affected participant: the agentive and the eventive constructions. The first one shows a specialization on positive affectation and the second one amply has a negative connotation. This suggests the necessity of properly distinguishing between two subtypes of affected datives: the benefactive and the malefactive. In this sense, it is possible to claim that Spanish belongs, at least partially, to the typological class of languages that formally code the difference between those semantic roles.

Keywords: affected dative; malefactive; benefactive; agentive constructions; eventive constructions. 


\section{Introducción}

De acuerdo con Radetzky y Smith (2010: 98-99), en términos tipológicos, las lenguas codifican a los benefactivos y los malefactivos de dos formas: i) colapsando la afectación en una única construcción, o bien ii) diferenciando la afectación positiva de la negativa mediante dos o más construcciones distintas. Los ejemplos (1) y (2) ilustran ambos mecanismos, respectivamente:

Checo (Janda, 1993: 57-58)

$\begin{array}{ccr}\text { (1) a. Ludmila mu uvařila } & \text { kaši } \\ \text { NOM } & \text { 3SG.DAT cocinó } & \text { kasha.AC } \\ \text { 'Ludmila le cocinó kasha' } & \\ \text { b. Aleš nám } & \text { naboural } & \text { auto } \\ \text { NOM IPL.DAT descompuso } & \text { auto.AC } \\ \text { 'Alešnos descompuso el auto' } & \end{array}$

Coreano (Lee, 1974: 151)

(2) a. na-nun Hanako-eykey mun-ul yele-cwu-ess-ta

Yo-top Hanako-dAT puerta-AC abrir-DAR-PRET-DECL

'Yo le abrí la puerta a Hanako'

b. ku sensayng-un haksayng-tul-eykey conkyeng-pat-nun-ta

el maestro-top estudiante-PL-AG respetar-PAS-PRES-DECL

'El maestro es respetado por los estudiantes'

c. pholo-ka henpieng-eykey kwutha-tangha-ess-ta

prisionero-s militar-Ag golpear-PAS-PRES-DECL

'El prisionero fue golpeado por un militar'

d. ce yeca-ka namphyen-eykey sopak-mac-ess-ta

esa mujer-s esposo-AG abandonar-PAS-PRES-DECL

'Esa mujer fue abandonada (fue víctima de abandono) por su esposo'

Las expresiones de (1) muestran que el checo utiliza una construcción con dativo para marcar tanto la afectación positiva como la negativa. En contraste, el coreano se vale de cuatro construcciones: dos para la afectación positiva (una activa y otra pasiva, con los morfemas -cwu-y-pat-) y dos para la afectación negativa (cada una con un morfema pasivo distinto -tangha-y-mac-).

Al igual que el checo, el español comúnmente se clasifica junto con las lenguas que no distinguen formalmente entre benefactivo y malefactivo (Smith, 2005, y Radetzky y Smith, 2010: 99), pues se arguye que cuenta con un recurso, la construcción de dativo de afectación, que semánticamente activa tanto una lectura de efecto positivo como una de efecto negativo.

El objetivo central de este trabajo es mostrar, a partir de un análisis semántico-sintáctico de datos de uso del español de México, que esta lengua cuenta con dos recursos gramaticales en proceso de especialización con los que formalmente se distingue la afectación positiva de 
la negativa: una construcción agentiva, que privilegia un efecto positivo para el participante codificado como dativo, y otra eventiva o no agentiva, especializada para activar el efecto negativo. Estas construcciones se ejemplifican en (3) y (4), respectivamente:

(3) Juan le compuso el carro a Pedro

(4) Se le descompuso el carro a Pedro

Los verbos componer y descomponer pertenecen al campo semántico de cambio de estado; por ello, únicamente requieren dos participantes, el que efectúa o causa el cambio y la entidad que lo sufre. En estas expresiones, Pedro no corresponde a uno de estos participantes; por lo tanto, no es un argumento, sino un adjunto codificado en la función central de dativo, es decir, es un dativo de afectación. Ahora bien, las construcciones de (3) y (4) son distintas; por un lado, en (3) un agente desencadena una afectación positiva; por otro lado, en (4) se alude a un efecto negativo y la presencia del clítico se permite presentar el evento como espontáneo, es decir, sin un agente que propicie el efecto adverso. Con efecto positivo y negativo nos referimos aquí, en primer lugar, a la inferencia semántico-pragmática que permite avalar, sin mayor sustancia lingüística, una interpretación positiva o negativa con los ejemplos respectivos, tal y como se puede ver abajo en las paráfrasis de los ejemplos (3) y (4), respectivamente:

(5) a. Juan compuso el carro en beneficio de Pedro

b. ?Juan compuso el carro en perjuicio de Pedro

(6) a. El carro se descompuso en perjuicio de Pedro

b. ?El carro se descompuso en beneficio de Pedro

A pesar de que es claro que en las oraciones de (3) y (4) la interpretación positiva o negativa está mediada por la semántica de los verbos núcleo, es también evidente que el tipo de construcción, la agentiva y la eventiva, influyen en la afectación de dos maneras. En primer lugar, las dos construcciones resaltan el valor inherente de los verbos, es decir, favorecen la afectación benéfica o adversa. Incluso con predicados cuyo significado no se inclina hacia un sentido u otro, cada construcción activa preferentemente uno de estos dos efectos. Así, es más probable que la interpretación de (7a) y (8a) sea de beneficio y la de (7b) y (8b) de perjuicio.

(7) a. Juan le derritió un bombón² a Pedro

b. Se le derritió un bombón a Pedro

2 Dulce de azúcar, de forma más o menos esférica o cilíndrica, muy suave y esponjoso, espolvoreado con azúcar glass, que al derretirse adquiere una consistencia cremosa; malvavisco: "Asamos salchichas y bombones en la fogata" (Lara, 2010). 
(8) a. Juan le marcó el teléfono a Pedro

b. Se le marcó el teléfono a Pedro

En segundo lugar, cada una de estas construcciones selecciona tipos de verbos distintos: la agentiva se inclina por verbos de semántica positiva (como componer), mientras que la eventiva se construye básicamente con predicados de semántica negativa (como descomponer). Además, la construcción eventiva selecciona predominantemente verbos que tienen un carácter causativo y que por lo tanto puedan alternar en una lectura anticausativa (descomponer/descomponerse). Más importante aún es el hecho de que esta construcción implica una pérdida de control, lo que de forma extensiva se interpreta negativamente.

Ahora bien, aunque es innegable que ambas construcciones pueden tener el efecto contrario, incluso con verbos tan cargados semánticamente hacia un tipo de afectación como componer y descomponer, también es cierto que para generar la lectura contraria se tiene que agregar mayor sustancia lingüística. Se trata, en este caso, de construcciones marcadas.

(9) a. Juan le compuso mal el carro a Pedro

b. Afortunadamente, se le descompuso el carro a Pedro, lo que impidió que estuviera presente en su trabajo durante el asalto

Así, los ejemplos de (9) muestran que existen interpretaciones favorecidas; por ello, es necesario agregar más información para cambiar el efecto de una construcción agentiva con componer y una eventiva con descomponer. Con el primer verbo basta con incorporar el adverbio mal; con el segundo, sin embargo, hay que agregar muchísimo más contexto para que el referente del dativo se interprete como un participante beneficiado.

Nótese, además, que aunque las construcciones agentivas son mucho más flexibles para aparecer con verbos inclinados al efecto adverso - como se observa en (10a) - , no ocurre lo mismo con las estructuras eventivas, cuya compatibilidad con una afectación positiva es más marcada:

(10) a. Juan le descompuso el carro a Pedro

b. Se le compuso el carro a Pedro

En efecto, la expresión de (10b) es muy poco compatible con una interpretación eventiva; su lectura más inmediata es la de una construcción impersonal en la cual se sobreentiende un agente, a pesar de que no está explicitado. Para hacer posible la lectura espontánea, se requiere mucho más contexto, como se observa en (11):

(11) pues ya se le compuso solito el carro a mi papá, quién sabe que tenía pero ya no hace ese ruido extraño 
Es poco probable que algo se componga por sí solo, es decir, sin la intervención de un agente; por ello, es necesario agregar más información para que la expresión sea comunicativamente más pertinente.

La poca compatibilidad entre el efecto positivo y las construcciones eventivas queda respaldada por los datos del corpus, puesto que efectivamente, al revisar qué tipo de afectación tienen estas, se identifica que, en términos de frecuencia, están sumamente especializadas en expresar un efecto adverso; en contraste, las construcciones agentivas tienden a manifestar un efecto benéfico.

En otras palabras, lo que aquí postulamos no es que el pronombre dativo posea una carga positiva o negativa; más bien sostenemos que codifica una afectación que tiende, en términos de frecuencia, a actualizarse positivamente en construcciones agentivas y negativamente en construcciones eventivas. El efecto, pues, de beneficio o de perjuicio es una propiedad de la construcción en general y no del pronombre ni del verbo por sí solos.

Con base en lo anterior, este estudio propone que el dativo de afectación se distribuye en dos tipos de construcciones básicas: las agentivas benefactivas y las eventivas malefactivas; en este sentido, consideramos que el español se sitúa en un punto intermedio entre las lenguas que colapsan la afectación en una misma macroestructura morfosintáctica y las que cuentan con un sistema de marcación diferenciado.

Para la obtención de los datos se revisaron las 108 entrevistas del Corpus Sociolingüístico de la Ciudad de México (CSCM) (Martín y Lastra, 2011-2015). Específicamente, se localizaron 877 casos con dativo de afectación. Cada uno de ellos se sometió a un análisis minucioso, que consistió en identificar las funciones sintácticas y semánticas de los participantes de cada oración y en determinar si la expresión configura un esquema construccional agentivo o eventivo.

Se trata, pues, de un estudio descriptivo basado en datos de uso, que tiene un enfoque funcionalista en sentido amplio, el cual subraya que los niveles sintáctico, semántico y pragmático son interdependientes y que las formas sintácticas están directamente relacionadas con las funciones comunicativas de la lengua (Dik, 1980, 1989). En particular, se pretende, más allá de un ánimo meramente clasificatorio, identificar el tipo de función comunicativa que tienen las construcciones con dativo de afectación en español y situarlas en un marco tipológico (Smith, 2005; Radetzky y Smith, 2010) que considera los tipos de mecanismos con los que las lenguas cuentan para señalar efectos positivos y negativos en un participante ajeno a la estructura eventiva de los predicados que son núcleos oracionales y, por lo tanto, ajeno también a la valencia verbal.

Esta introducción constituye la primera sección de las cinco con las que cuenta el artículo. La segunda versará sobre el dativo en español. En concreto, se hablará de los distintos 
tipos de dativos — regidos y no regidos - con especial énfasis en un subtipo de los no regidos, el de afectación. La tercera se centrará en las construcciones agentivas benefactivas; la cuarta, en las construcciones eventivas malefactivas. Por último, en la quinta sección, a manera de conclusión, se destacarán los principales aportes de este estudio.

\section{El dativo en español}

Por un lado, el término dativo se utiliza para referirse a la distinción de caso que se conserva en el paradigma de los clíticos pronominales me, te, le, nos, les y se, correlacionados con la función sintáctica de complemento indirecto (Bello, 1988 [1847]; Gili, 1979 [1948]; Fernández, 1987 [1951]; Seco, 1989 [1930]; RAE, 1973; Demonte, 1994a, 1994b, 1995; Romero, 2008; RAE y ASALE, 2009). Por otro, algunos autores se valen de este término únicamente para referirse a los participantes no regidos por el verbo que se codifican mediante los clíticos de dativo (Gutiérrez, 1977, 1999; Hernanz y Brucart, 1987; Alarcos, 1994; Cifuentes y Llopis, 1996; Di Tullio, 1998; Di Tullio y Malcuori, 2012). Otros autores (Seco, 1989 [1930]; Martín, 1974; Fernández, 1987 [1951]; Masullo, 1992; Porto, 1992; Delbecque, 1992; Delbecque y Lamiroy, 1996; Maldonado, 1994, 2002; Romero, 2008), por el contrario, tienen una perspectiva más amplia -que, por cierto, coincide con la nuestra- de lo que puede abarcar este término y cubren con él tanto a los participantes regidos como a los no regidos; desde esta aproximación, el dativo puede entenderse como una función morfosintáctica que se codifica mediante las construcciones de doblado, conformadas por el clítico pronominal de dativo y una frase prepositiva encabezada por a, o por medio del clítico, como se muestra en (12) y (13) respectivamente:

(12) a. Juan le dio una tarjeta a María

b. Juan le hizo una tarjeta a María

(13) c. Juan le dio una tarjeta

b. Juan le hizo una tarjeta

Es común también denominar esta función como complemento indirecto u objeto indirecto (Gili, 1979 [1948]; RAE, 1973; Alcina y Blecua, 1975; Cano, 1981; Hernanz y Brucart, 1987; Alarcos, 1994; Vázquez, 1995; Goldberg, 1995; Cifuentes y Llopis, 1996; Gutiérrez, 1999; Company, 2006; Ortiz, 2006; Becerra, 2007; RAE y ASALE, 2009). Sin embargo, este trabajo parte de la idea de que el dativo es un término más conveniente para referir esta función, en tanto que permite enmarcar dentro del fenómeno de la datividad todas las variaciones semánticas y sintácticas en las que el clítico prononimal aparece, unas veces de forma obligatoria, como se ejemplifica en (14) y (15), otras de manera optativa, pero recurrente, como se ilustra en (16):

(14) a. *A él gustan las manzanas

b. A él le gustan las manzanas 
(15) a. ?Juan preparó un pastel a Pedro

b. Juan le preparó un pastel a Pedro

(16) a. Juan dijo la verdad a Pedro

b. Juan le dijo la verdad a Pedro

En efecto, para verbos como gustary preparar la codificación del clítico tiene un grado mayor de obligatoriedad, mientras que para verbos como decir, que sí pueden prescindir de él, la codificación más recurrente es también la que incluye el clítico de dativo.

\subsection{Dativos regidos y no regidos}

Los dativos regidos, denominados también dativos argumentales, léxicos o nucleares, se caracterizan por codificar a uno de los participantes que forma parte de la valencia verbal, es decir, de la selección léxica de cada uno de los verbos que fungen como núcleos oracionales. En la bibliografía se han identificado tres tipos de dativos regidos: i) con verbos de transferencia (Cano, 1981; Delbecque, 1992; Demonte, 1994a, 1994b, 1995; Vázquez, 1995; Delbecque y Lamiroy, 1996; Newman, 1996; Shibatani, 1996; Gutiérrez, 1999; Maldonado, 2002; Ortiz, 2006; Conti, 2008; RAE y ASALE, 2009) - como dar y decir en (17) - ii) con verbos seudoimpersonales (Melis y Flores, 2007) - tal es el caso de gustar y tocar en (18) - y iii) con verbos de cambio de locación (Cifuentes y Llopis, 1996; Maldonado, 2002; Ibáñez, 2004) — como echar y sacar en (19)—:

(17) a. nos dio como treinta pesos/ que para el chesco (CSCM)

b. él me dijo que fueron como muchos los requisitos (CSCM)

(18) a. a mí me gusta dedicarme a varias cosas (CSCM)

b. me tocaba que yo saliera al día siguiente (CSCM)

(19) a. me dan miedo [los gallos] porque mi abuelita me echó un gallo (CSCM)

b. tú vas a un espectáculo donde haya aglomeración de gente/ te sacan la cartera sin sentirla (CSCM)

Los verbos de transferencia son aquellos que seleccionan tres participantes: un agente, un tema y un receptor. En el evento de la transferencia el agente transmite algo al receptor, ya sea materialmente, cuando lo que se transmite es algo tangible, como se observa en (17a), o de manera abstracta, cuando se trata de algo intangible, como se muestra en (17b). En español el receptor típicamente se codifica como dativo.

Los verbos seudoimpersonales han sido identificados para el español como una clase de verbos que se caracteriza por: i) poseer un significado especializado en valores modales, existenciales y de afectación psíquica; ii) seleccionar de manera preferente sujetos de tipo oracio- 
nal, y iii) incluir un argumento (cuyo referente es casi siempre humano) codificado como dativo y en una posición preverbal (Melis y Flores, 2007). Algunos ejemplos de los verbos que pertenecen a esta clase son: parecer, tocar, costar, gustar, agradar, alcanzar, faltar, sobrar, entre otros.

Los verbos de cambio de locación, por su parte, se distinguen de los de transferencia porque su tercer participante no es propiamente un receptor, sino que más bien se trata de una locación, tipo meta, como se observa en (19a) con el verbo echar, o tipo fuente, como se muestra en (19b) con el verbo sacar. Así pues, en tanto que la locación es un participante exigido por el verbo (Ibáñez, 2004), cuando aparece codificada como dativo, sigue siendo un argumento.

Por el contrario, los dativos no regidos no forman parte de la selección léxica del verbo, se trata de participantes no argumentales codificados en la función central de dativo; por ello, constituyen un caso particular de aplicativo (Ibáñez, 2003; RAE y ASALE, 2009: § 35.1C), entendido este último como un recurso morfosintáctico mediante el cual se codifican participantes periféricos como centrales. Los verbos que típicamente incluyen este tipo de dativos pertenecen a los campos semánticos de creación - como hacer en (20a) - y de cambio de estado - por ejemplo, componer en (20b)-.

(20) a. le hizo el dibujo (CSCM)

b. le compuse mucha ropa a la directora (CSCM)

Tanto los verbos de cambio de estado como los de creación configuran un marco semántico propicio para integrar dativos no regidos, a saber, el de resultado causado (Boneh y Nash, 2013), que implica que un agente causa algo ya sea creando, destruyendo o modificando una entidad. El resultado causado puede afectar positiva o negativamente a otros participantes, los cuales, cuando se incluyen en el evento, se codifican en función de dativo.

En tanto que los dativos regidos forman parte de la selección léxica, si se omiten se generan expresiones semánticamente anómalas (o que requieren un contexto adecuado para su interpretación, en el cual es posible recuperar al participante elidido), como se ejemplifica en (21); por el contrario, los dativos no regidos se eliden sin problemas, así se observa en (22):

(21) a. ?Juan dio una manzana

b. *Gusta caminar

c. ?Echó agua

(22) a. Juan hizo la cena

b. Juan pintó la casa

Hasta aquí pareciera que las diferencias entre dativos regidos y no regidos son solo de orden léxico-semántico; sin embargo, existen también comportamientos sintácticos distintos; por 
ejemplo, Demonte (1994b) e Ibáñez $(2003,2006)$ consideran que las frases de dativo no regidas del español requieren obligatoriamente de la presencia del clítico pronominal, como se observa en (23), en contraste con los regidos que pueden prescindir de este, así se ejemplifica en (24):

(Ibáñez, 2006: 722)

(23) a. *Juan rompió la pierna a Pedro

b. Juan le rompió la pierna a Pedro

(24) a. Las mamás siempre tratan de dar buenos consejos a los niños

b. Las mamás siempre les tratan de dar buenos consejos a los niños

Asimismo, Demonte señala que solo los sustantivos derivados de un verbo de tres argumentos con dativo regido aceptan un segundo complemento introducido por la preposición a; en contraste, los sustantivos de verbos de resultado causado no lo admiten:

(1994b: 465)

(25) La entrega / venta / donación / devolución del libro a Manolo se llevó a cabo hace cinco días.

(26) La preparación del pastel (*a la niña) / el arreglo del coche (*a mi hermana) / el lavado de la camisa (*a Dionisio) / la reparación de la terraza (*a Magda) se hará la semana próxima.

Además, los dativos argumentales no aceptan del todo paráfrasis con frases prepositivas, como se ilustra en (27); por el contrario, al sustituir los dativos no regidos por estas frases se obtienen expresiones comunes en el español, así lo muestran las expresiones de (28):

(27) a. Juan le dijo la verdad a María

a'. ?Juan dijo la verdad para María

b. Juan le quitó el dinero a María

b. ?Juan quitó el dinero de María

(28) a. Juan le preparó la cena a María

a’. Juan preparó la cena para María

b. Juan le lavó la ropa a María

b’. Juan Iavó la ropa de María

\subsection{Los dativos no regidos}

En la bibliografía se han propuesto varias clasificaciones de los dativos no regidos en español. En general, la mayoría de los autores coinciden en identificar tres tipos: Ios benefactivos, los 
posesivos y los éticos. Sin embargo, hay variación en la nomenclatura, como lo muestra la siguiente tabla, que incluye dos columnas: la primera permite ver los nombres que le asigna cada autor a estos tres tipos y la segunda ofrece un ejemplo prototípico.

\section{TABLA 1}

Variación en la nomenclatura de los dativos no regidos

\section{TÉRMINOS}

\section{EJEMPLOS}

- Benefactivo (Demonte, 1994a, 1994b, 1995; Shibatani, 1996; Gutiérrez, 1999; Becerra, 2007; Di Tullio y Malcuori, 2012)

- Benefactivo/Malefactivo (Radetzky y Smith, 2010)

- Commodi/Incommodi (Fernández, 1987 [1951])

- Complemento independiente (Martín, 1974) Juan le hizo un dibujo

- De afectación (Maldonado, 1994, 2000, 2002)

- De interés (RAE, 1973; RAE y ASALE, 2009)

- De interés o commodi/incommodi (Porto, 1992; Romero, 2008)

- Posesivo (RAE, 1973; Delbecque, 1992; Delbecque y Lamiroy, 1996; Cifuentes y Llopis, 1996; Di Tullio, 1998; Becerra, 2007; Conti, 2011; Di Tullio y Malcuori, 2012)

- Posesivo o Simpatético (Fernández, 1987 [1951]; Alcina y Blecua, 1975; Gutiérrez, 1977, 1999; Romero, 2008; RAE y ASALE, 2009)

Juan le lavó los cabellos Le duele la cabeza

- Simpatético (Martín, 1974; Porto, 1992; Demonte, 1994a)

- De interés (Seco, 1989 [1930]; Maldonado, 1994)

- Ético (Fernández, 1987 [1951]; RAE, 1973; Martín, 1974; Alcina y Blecua, 1975; Gutiérrez, 1977; Delbecque, 1992; Cifuentes y Llopis, 1996; Di Tullio, 1998; Becerra, 2007; Romero, 2008; RAE y ASALE, 2009; Di Tullio y Malcuori, 2012)

- Ético o de interés (Gili, 1979 [1948])

- Expresivo o ético (Delbecque y Lamiroy, 1996)

- Simpatético (Maldonado, 2002)

- Superfluo (Bello, 1988 [1847]; Company, 2006)

- Superfluo o de interés (Alarcos, 1994; Gutiérrez, 1999)

- Superfluo o ético (Porto, 1992)

Ahora bien, las divergencias van más allá de la terminología; se concentran principalmente en la delimitación de cada categoría. En primer lugar, se habla de dativos no regidos para referirse a algunos participantes del tipo receptor, meta y fuente, que son parte de la valencia semántica de cierto tipo de verbos:

(Gutiérrez, 1999: § 30.6.3)

(29) a. Irene no habla con Adela

b. Rosa colocó una pegatina en el coche

c. María robó el dinero de Juan

Otra vez me llegó tarde No me le des azúcar al niño 
(30) a. Irene no le habla a Adela

b. Rosa le colocó una pegatina al coche

c. María le robo el dinero a Juan

Gutiérrez considera que hay una promoción sintáctica en la que las frases prepositivas de (29) se vuelven dativo en (30). En otros términos, para este autor los dativos de hablar, colocar y robar no son participantes de base; por ello, los engloba junto con los complementos indirectos no argumentales. Sin embargo, en los tres ejemplos, el dativo codifica un argumento: un receptor en (30a), una meta en (30b) y una fuente en (30c).

En segundo lugar, las delimitaciones de los tipos de dativo no regidos comunes en la bibliografía no funcionan porque se incorporan en una misma categoría los dativos de posesión alienable e inalienable (Fernández, 1987 [1951]: §§ 105/104.1-2; Alcina y Blecua, 1975: 867-868; Porto, 1992: 34; Delbecque, 1992: 128-130; Delbecque y Lamiroy, 1996: 96-97; Di Tullio, 1998: 109; Gutiérrez, 1977: 416; 1999: §§ 30.6.5.1-4; Romero, 2008: 38-42; RAE y ASALE, 2009: §§ 35.7f-j; Becerra, 2007: 269-276), a pesar de que —como bien lo señalan Di Tullio y Malcuori, 2012: 358- manifiestan un comportamiento sintáctico distinto: Ios primeros son opcionales; los segundos, obligatorios, así se observa en (31) y (32), respectivamente.

(31) a. Juan me arregló el carro

b. Juan arregló mi carro

(32) a. Juan me quebró la cabeza

b. ?Juan quebró mi cabeza

El dativo de (32) es obligatorio en virtud de que la relación de posesión es inalienable; en este caso con la construcción sin dativo de (32b) se genera una anomalía semántica porque parece que la cabeza es una entidad independiente y que hay menos afectación; por el contrario, en (31) se trata de una relación alienable entre el poseedor y lo poseído, por eso el clítico es prescindible. Nótese, además, que el efecto es distinto en las construcciones de (31a) y (32a) si se agrega un complemento adnominal que introduzca un poseedor:

(33) a. Juan me arregló el carro de María

b. ?Juan me quebró la cabeza de María

Efectivamente, si bien ambas estructuras son posibles, claramente resulta más forzada la de (33b), porque va contra lo esperable que el referente del dativo no sea el poseedor de la cabeza.

En tercer lugar, otra discrepancia en las clasificaciones se observa en el tipo de estructuras en las que aparece el dativo ético. En efecto, a pesar de que existe acuerdo en incluir dentro de esta categoría a los clíticos de primera persona que se incorporan a las expresiones 
que ya cuentan con dativo - ejemplo (34) - algunos autores la extienden de distintas maneras. Así, para Martín (1974), incluye estructuras de dativo posesivo — como la de (35)—; para Gili (1979 [1948]) y Alarcos (1994), de dativo concordado, denominado dativo aspectual por la RAE y la ASALE (2009) —como la de (36)—, y para Gutiérrez (1999), se extiende a las terceras personas - ejemplo (37)-:

(Alarcos, 1994: § 351)

(34) No me le deis caramelos

(Martín, 1974: 79)

(35) Melloran los ojos

(Gili, 1979 [1948]: § 58)

(36) Ella se tomó el café

(Gutiérrez, 1999: § 30.7.4.3)

(37) El tutor les gastó toda la herencia de su hijo Luis

Por todo lo anterior, a pesar de que no se encuentra en los horizontes de este estudio analizar cabalmente los distintos tipos de dativos no regidos, resulta pertinente sugerir una caracterización de ellos que sirva como punto de partida para nuestro análisis del dativo de afectación.

\subsubsection{Esbozo de un panorama de los dativos no regidos}

Coincidimos con la bibliografía en que existen al menos tres tipos de dativos no regidos:

1. El dativo parte-todo, que preferimos denominar de esta forma y no posesivo porque solo se restringe a las relaciones de posesión inalienable.

2. El dativo de afectación (Maldonado, 1994, 2000, 2002), término adecuado para este estudio, porque dialoga con las investigaciones tipológicas que hablan sobre el participante afectado (Chung, 1993; Smith, 2005; Radetzky y Smith, 2010). Resulta confuso llamarlo dativo de interés, en tanto que se ha usado este nombre para referirse al dativo ético (Seco, 1989 [1930]; Gili, 1979 [1948]; Maldonado, 1994), o benefactivo, puesto que sugiere que no hay afectación negativa y además se ha utilizado para aludir a los participantes animados no argumentales introducidos por la preposición para (Di Tullio, 1998; Maldonado, 1994, 2000, 2002; Becerra, 2007; Di Tullio y Malcuori, 2012).

3. El dativo ético, que se restringe, como lo sugieren Gutiérrez $(1977,1999)$ y Delbecque (1992), al clítico que coaparece con otros dativos. 
Ahora bien, a pesar de que nuestra clasificación dialoga con las otras, se distingue de ellas en que se establece a partir de la distribución de cuatro rasgos: dos de orden semántico y dos de orden sintáctico. Con respecto a los primeros, se evalúa la animacidad del referente del dativo y si la relación de posesión que establece con el paciente es alienable o inalienable. En cuanto a los segundos, se considera si la codificación con dativo es obligatoria u opcional y si puede coaparecer con otros dativos. La siguiente tabla indica los rasgos que tiene cada tipo de dativo e incluye un ejemplo para cada rasgo.

\section{TABLA 2}

Clasificación de los dativos no regidos con base en sus rasgos

\begin{tabular}{|c|c|c|}
\hline DATIVOS & RASGOS & EJEMPLOS \\
\hline Parte-todo & $\begin{array}{c}\text { Posesión inalienable } \\
\text { Inanimado } \\
\text { Animado } \\
\text { Codificación obligada con animados }\end{array}$ & $\begin{array}{c}\text { Juan le torció el brazo a Pedro } \\
\text { Juan le ponchó las Ilantas al carro } \\
\text { Ráscame la espalda } \\
\text { ?Rasca } \varnothing \text { mi espalda }\end{array}$ \\
\hline De afectación & $\begin{array}{c}\text { Animado } \\
\text { Codificación opcional } \\
\text { Posesión alienable }\end{array}$ & $\begin{array}{l}\text { Juan le hizo un pastel a María } \\
\text { Juan } \varnothing \text { hizo un pastel } \\
\text { Juan le cosió su suéter a María }\end{array}$ \\
\hline Ético & $\begin{array}{l}\text { Animado (Interlocutor) } \\
\text { Codificación opcional } \\
\text { Coaparece con otros dativos }\end{array}$ & $\begin{array}{c}\text { No me le des de comer tanto al niño } \\
\text { No } \varnothing \text { le des de comer tanto al niño } \\
\text { Me le torcieron el brazo a mi hijo }\end{array}$ \\
\hline
\end{tabular}

De acuerdo con la tabla 2, cada uno de los dativos tiene tres rasgos semántico-sintácticos. El dativo parte-todo alude a relaciones de posesión inalienable, incluye tanto referentes animados como inanimados y su codificación tiene un mayor grado de obligatoriedad cuando el referente es una entidad animada. Por su parte, en nuestra propuesta, el dativo de afectación se distingue del anterior en que sus referentes son siempre animados, su codificación sintáctica es opcional y establece relaciones de posesión alienables. Por último, la tabla 2 indica que el dativo ético refiere únicamente a los interlocutores del evento comunicativo, se codifica de manera opcional y aparece siempre con otros dativos.

El esbozo de un panorama de los dativos no regidos que hemos sugerido en esta sección debe entenderse como una hipótesis que requiere ser comprobada mediante un estudio de corpus, que someta a un análisis semántico-sintáctico minucioso cada uno de los ejemplos, con el propósito de verificar la validez de esta clasificación y de determinar cabalmente cuáles son las características de cada tipo de dativo no regido y los diagnósticos que permiten distinguirlos. Así pues, el objetivo de esta sección ha sido situar dentro de los dativos no regidos nuestro objeto de estudio: el dativo de afectación. A continuación, veremos los mecanismos más típicos de codificación del participante afectado en otras lenguas y las dos formas en que translingüísticamente se suele tratar a este participante, a saber, colapsando 
la afectación en una macroestructura o diferenciando el efecto benéfico del perjudicial mediante construcciones distintas.

\subsection{El participante afectado}

Se ha usado el término participante afectado para referirse a los benefactivos y malefactivos, es decir, a los participantes típicamente animados que sufren una afectación positiva o negativa -en principio, los referentes inanimados no son capaces de experimentar un beneficio o un perjuicio (Kittilä y Zúñiga, 2010: 6-7)—. Así lo hacen autores como Chung (1993), Smith (2005) y Radetzky y Smith (2010), que aluden a la construcción de afectación. Por su parte, Kittilä y Zúñiga identifican los cuatro mecanismos más frecuentes tipológicamente para la codificación del participante afectado:

1. Caso morfológico, el dativo es el más frecuente translingüísticamente, aunque también se utilizan casos como el alativo y el ablativo:

Latín (Van Hoecke, 1996: 8)
(38) Sol
omn-ibus lucet
sol.nOm todos-Dat brilla
'El sol brilla para todos'
(Petronius, Satyricon, 100)

Finlandés (Kittilä y Zúñiga, 2010: 7)
(39) Henkilö
ava-si
ove-n
yksilö-lle
'La persona le abrió la puerta al individuo'

Kuuk thaayorre (Kittilä y Zúñiga, 2010: 8)

$\begin{array}{llll}\text { (40) Nhangun may } & \text { yump } & \text { ngathanma } \\ \text { 3SG.DAT comida hacer. IMP } & \text { ISG.ABL } \\ \text { 'Hazle la comida por mi' } & \end{array}$

2. Adposiciones, ya sea preposiciones o posposiciones.

Islandés (Kittilä y Zúñiga, 2010: 8)
(41) Hann lagði
bílnum
fyrir mig
3SG.NOM estacionó carro.AC por ISG.AC
'Él estacionó el carro por mí

Finlandés (Kittilä y Zúñiga, 2010: 8)
(42) Men-i-n kaupunki-in häne-n harmikse-en
ir-PRET-ISG ciudad-IL 3SG-GEN en perjuicio-3SG
'Fue a la ciudad en perjuicio de él/ella'


3. Verbos seriales, es decir, auxiliares verbales que muchas veces están desprovistos de su sentido original. El más común es el verbo dar, aunque también se utilizan otros, por ejemplo, reemplazar.

Tailandés (Lord y otros, 2002: 220)

(43) Kháw thamyaan hây phîichaay

3sg trabaja dar hermanomayor

'Él trabaja para su hermano mayor'

Tailandés (Jenny, 2010: 380)

$\begin{array}{llll}\text { (44) Kháw pay talaàt } & \text { thecn } & \text { phî̀n } \\ \text { 3sg va mercado reemplazar } & \text { amigo } \\ \text { 'Él va al mercado en lugar de su amigo' } & \end{array}$

4. Aplicativo, es decir, una marca morfológica en la base verbal.

Kunuz de Nubia (Abdel-Hafiz, 1988: 114)
(45) a. Id
ay-gi ba:b-ki
alle-de: $n-s-u$
hombre ISG-AC puerta-AC arreglar-APL-PRET-3SG
'El hombre me arregló la puerta'
$\begin{array}{cll}\text { b. Ay-gi } & \text { ir:-g } & \text { noddi-de:S-S-a } \\ \text { ISG-AC } & \text { cuerda-AC } & \text { cortar-APL-PRET-3PL }\end{array}$
'Me cortaron la cuerda' (la afectación es negativa)

De las cuatro alternativas para la introducción del participante afectado, el español se vale de dos: Ia de adposición, mediante las preposiciones para y por, ejemplificadas en (46), y la de aplicativo, en tanto que, como lo reconocen Ibáñez (2003) y la RAE y ASALE (2009: \$35.1C), el clítico de dativo le da un estatus sintáctico central a los participantes periféricos:

(46) a. Juan compró un juguete para sus hijos

b. Juan hizo la tarea por sus hijos

(47) a. Juan le/les compró un juguete a sus hijos

b. Juan le/les hizo la tarea a sus hijos

Con respecto a la distinción entre benefactivo y malefactivo, Radetzky y Smith (2010) señalan que, por un lado, lenguas como el alemán, el islandés, el latín, el francés, el polaco, el checo, el lezguiano, el húngaro y el vasco cuentan con una construcción de afectación que colapsa en una única macroestructura los significados benéficos y adversos; mientras que otras, como el marathi, el maithili, el telugu, el tamil, el tailandés, el vietnamita, el lai, el lahu, el mandarín, el hakka, el japonés y el coreano, cuentan con construcciones morfosintácticas que diferencian la afectación positiva de la negativa. Un ejemplo de las primeras se observa en la construcción agentiva con el clítico pronominal de dativo del francés: 
(48) a. Je lui ai fait un gâteau

'Le hice un pastel'

b. Je lui ai fait un très mauvais repas

'Le hice una comida muy mala'

En contraste, una lengua como el japonés se vale de distintas marcas morfológicas para distinguir la afectación positiva de la negativa:

Japonés (Shibatani, 1996: 175-176)

(49) Kyoo Taroo ga Hanako ni hon o yonde yatta

Hoy Taro Nom Hanako dat libro ac leer dar

'Hoy Taro le lee un libro a Hanako' (lit. Taro dar-leer un libro a Hanako)

Japonés (Tsuboi, 2010: 420)

$\begin{array}{llll}\text { (50) } & \text { Taro-wa Hanako-ni } & \text { piano-o hik-are-ta } \\ \text { Taro-top Hanako-dat } & \text { piano-Ac } & \text { tocar-pas-PRET }\end{array}$

'Taro (fue afectado negativamente porque) fue tocado el piano por Hanako'

En (49) la afectación de Hanako es necesariamente positiva, porque el verbo yatta no se utiliza para la afectación negativa. Por el contrario, en (50) Taro obligatoriamente recibe una afectación negativa, puesto que el sufijo pasivo -(r)are no da lugar a otra interpretación que no sea la adversativa.

El español se ha agrupado junto con las lenguas que colapsan la afectación positiva y negativa en una misma macroestructura (Smith, 2005; Radetzky y Smith, 2010: 99); pareciera que dicha clasificación es pertinente, sobre todo si se consideran expresiones como las de (51):

(51) a. un carpintero me barnizó una puerta (CSCM)

b. pero te va a deshacer la casa un día de estos (CSCM)

Es evidente que en (51a) el referente del dativo recibe un efecto positivo de la acción que realiza el agente. En contraste, en (51b), el efecto es negativo. No obstante, ambos casos tienen la misma estructura semántico-sintáctica, puesto que cuentan con un S (Ag), un OD (Pte) y un dativo de afectación.

Ahora bien, como mostraremos más adelante, el español se distingue de lenguas como el alemán, el islandés, el latín, el francés, entre otras, en que cuenta con una construcción especializada para la afectación negativa:

(52) el pantalón se me mojó (CSCM) 
En (52) se observa una construcción formada por un sujeto tipo paciente (el pantalón), el clítico se, el dativo (me) y un verbo de cambio de estado. Nótese que no interviene ningún agente en la afectación negativa, más bien es un evento accidental el que produce el efecto adverso.

Así pues, el español no colapsa completamente la afectación positiva y negativa en una misma estructura, puesto que, si bien esto ocurre con las construcciones agentivas, las eventivas, como veremos más adelante, tienden abrumadoramente, en términos de frecuencia, a tener una carga negativa, de tal manera que resulta pertinente ubicar al español en un punto intermedio entre las lenguas que distinguen la afectación y las que la colapsan. A continuación, veremos de forma más detallada cuál es la estructura de cada una de estas construcciones y la frecuencia con la que aparecen en el corpus.

\subsubsection{Dos construcciones básicas con dativo de afectación}

Como ya se mencionó, en español el dativo de afectación puede tener tanto un efecto positivo como negativo; sin embargo, dicho efecto está condicionado, en términos de frecuencia, por el tipo de construcción. Consecuentemente, hemos definido dos tipos de construcciones básicas con base en la presencia o ausencia de un agente y el tipo de afectación desencadenada: las agentivas benefactivas y las eventivas malefactivas. Sus versiones más típicas en términos estructurales se ejemplifican en (53) y (54), respectivamente, y aparecen además con las funciones semánticas y sintácticas desglosadas:

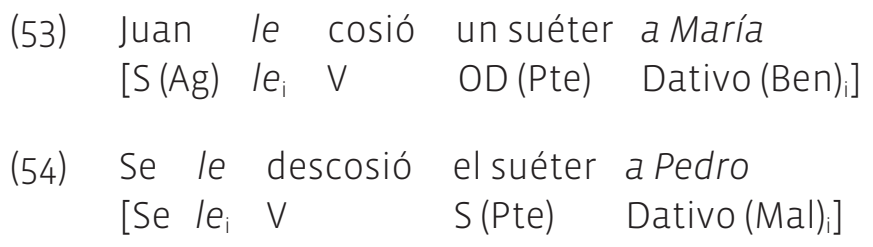

En el ejemplo (53), el verbo coser cuenta con tres participante que semánticamente cumplen las funciones de agente (Juan), paciente (un suéter) y benefactivo (a María), y sintácticamente, las de sujeto, objeto directo y dativo, respectivamente. En estas construcciones, la afectación es desencadenada por un agente y además suele ser positiva, por eso se le denomina benefactivo al participante codificado como dativo.

Por su parte, en el ejemplo (54), el verbo descoser cuenta únicamente con dos participantes que desempeñan semánticamente las funciones de paciente (el suéter) y malefactivo (a Pedro), y sintácticamente, las de sujeto y dativo, respectivamente. En este tipo de casos, el clítico se contribuye a presentar el evento como espontáneo, es decir, que ocurre sin la intervención de un ser humano. La afectación de las expresiones con la estructura semánticosintáctica del ejemplo (54) es casi siempre negativa; por ello, se le denomina malefactivo al participante codificado como dativo. 
Ahora bien, no es el pronombre el que determina el efecto benéfico o adverso, ni tampoco lo hacen el verbo o el contexto comunicativo por sí solos, a pesar de tener cierta influencia; más bien, proponemos que el tipo de afectación está supeditado a las construcciones en dos formas: por un lado, la eventiva selecciona verbos de semántica negativa, y la agentiva, verbos de semántica positiva; por otro, la construcción en sí misma contribuye a resaltar uno de estos dos efectos. Efectivamente, la construcción eventiva implica que no hay control sobre el evento denotado por el verbo, lo cual generalmente se relaciona con situaciones adversas; en consecuencia, selecciona predicados que no pueden incluir un agente - como los de las expresiones de (55) - o que al incorporarse a esta estructura dejan de tener la posibilidad de incluirlo, así se observa en (56):

(55) a. *Juan murió a Pedro

b. *Juan caducó los dulces

(56) Se me descompuso/rompió/extravió el teléfono *por Pedro

Por su parte, la construcción agentiva implica un grado de control que, si bien puede utilizarse para desencadenar efectos adversos, a la luz de nuestro corpus, afirmamos que suele usarse para generar efectos positivos; por consiguiente, tiende a seleccionar predicados que típicamente aparecen con agentes y que son reticentes a no incluirlos:

(57) a. Juan reparó el lavabo

b. ?La casa se reparó (sola)

(58) a. Juan preparó un pastel

b. ?El pastel se preparó (solo)

La prueba de que la construcción exalta un tipo de efecto es que, con predicados cuyo significado está menos cargado hacia lo positivo o negativo, es la construcción la que determina la afectación:

(59) a. Juan me formateó mi computadora (efecto positivo)

b. Se me formateó mi computadora (efecto negativo)

Además, cuando el verbo tiene una ligera carga hacia uno u otro efecto, la construcción es capaz de revertir la afectación, como se observa en (60), o al menos crear un contexto ambiguo con las dos interpretaciones, así se advierte en (61):

(60) a. Juan me encendió la tele (efecto positivo)

b. Se me encendió la tele (efecto negativo) 
(61) a. Se me apagó la tele

b. Juan me apagó la tele (efecto negativo)

(efecto positivo o negativo)

Veamos ahora cómo se distribuyen en nuestro corpus las construcciones agentivas benefactivas y las eventivas malefactivas:

\section{TABLA 3}

Frecuencias de construcciones agentivas y eventivas

\begin{tabular}{ccc} 
CONSTRUCCIONES & CASOS & PORCENTAJE \\
\hline Agentivas benefactivas & 783 & $89.28 \%$ \\
\hline Eventivas malefactivas & 94 & $10.72 \%$ \\
\hline Total & $\mathbf{8 7 7}$ & $\mathbf{1 0 0 \%}$ \\
\hline
\end{tabular}

La tabla 3 permite ver que, de los 877 ejemplos con dativos de afectación, el 87.69\% corresponde a estructuras agentivas y el $12.31 \%$ a eventivas, lo que equivale a 769 y 108 casos, respectivamente. Esto no resulta extraño, de hecho Smith (2010) señala que translingüísticamente las construcciones agentivas benefactivas son más frecuentes y más básicas que las eventivas, puesto que no todas las lenguas cuentan con estas últimas.

En las siguientes secciones, analizaremos de forma detenida cada grupo de construcciones: las agentivas de efecto positivo, o benefactivas, y las eventivas, de efecto negativo, o malefactivas. En concreto, la sección (3) se concentrará en los tipos de construcciones agentivas y en la clasificación semántica de los benefactivos. Por su parte, la sección (4) se dedicaráa a las construcciones eventivas y a los tipos de malefactivos.

\section{Construcciones agentivas benefactivas}

\subsection{Tipos de construcciones agentivas}

Las construcciones agentivas se distribuyen en siete subtipos construccionales distintos. A continuación, se enumera cada uno de ellos, se indican sus funciones semánticas y sintácticas y se proporciona un ejemplo:

I. $\quad\left[S(A g)+\mathrm{Cl}_{i}+\mathrm{V}+\mathrm{OD}(\right.$ Pte/Tema $)+$ Dat (Ben) $]$

(62) y yo [...] le compraba sus blusitas de tirantes (CSCM)

II. $\quad\left[S(A g)+C l_{i}+V+\varnothing(\right.$ Pte $)+$ Dat (Ben) $]$

(63) ¿cada cuánto les limpia? [a los gallos] (CSCM) 
III. $\quad\left[\mathrm{S}(\mathrm{Ag})+\mathrm{Cl}_{i}+\mathrm{V}+\mathrm{FP}(\right.$ de comer $\left.)+\operatorname{Dat}(\text { Ben })_{i}\right]$

(64) la señora nos preparaba de comer (CSCM)

IV. $\quad\left[\mathrm{S}(\mathrm{Ag})+\mathrm{Cl}_{\mathrm{i}}+\mathrm{V}+\right.$ Pred. Sec. + OD (Pte) + Dat (Ben) $]$

(65) les tenía bien limpiecito todo [a mis jefes] (CSCM)

V. $\quad\left[S(A g)+\mathrm{Cl}_{i}+\mathrm{V}+\mathrm{OD}(\right.$ Tema $)+\mathrm{OP}($ Loc $)+$ Dat (Ben) $]$

(66) ya te voy a echar tus condones en tu mochila ¿eh? (CSCM)

VI. $\quad\left[\mathrm{S}(\mathrm{Ag})+\mathrm{Cl}_{i}+\mathrm{V}+\mathrm{Dat}(\text { Ben })_{i}\right]$

(67) confió en mí porque pues las veces que le he trabajado me dice "sale échatelo" (CSCM)

VII. $\quad\left[\right.$ Sepas $\left.+\mathrm{Cl}_{i}+\mathrm{V}+\mathrm{S}(\mathrm{Pte})+\operatorname{Dat}(\text { Ben })_{i}\right]$

(68) es que ahora cuando una mamá se divorcia/ o se separa// se le hace una despedida de casada (CSCM)

La construcción I engloba los casos prototípicos con dativo benefactivo. En el ejemplo (62) se observa que el verbo comprar, además de incluir un sujeto agente (yo) y un objeto directo con la función semántica de tema (sus blusitas de tirantes), incorpora al benefactivo mediante el clítico de dativo le.

La construcción II es similar a la I; sin embargo, hay una clara diferencia: Ios casos de II no codifican sintácticamente el objeto directo. Así lo demuestra el ejemplo (63), en el cual el verbo limpiar aparece sin una frase nominal de objeto directo (esta ausencia se representa en la construcción con el símbolo $\varnothing$ ), únicamente incluye un sujeto agente, marcado en la flexión verbal, y el dativo benefactivo les, cuyo referente son los gallos. Ahora bien, es indudable que hay algo que es limpiado; por ello, se incluye en la construcción la función semántica de paciente.

La construcción III tampoco cuenta con un objeto directo; no obstante, el ejemplo (64) deja ver que se distingue de la II, puesto que el verbo preparar, además de contar con un sujeto agente (la señora) y un dativo benefactivo (nos), incluye la frase prepositiva de comer.

La construcción IV mantiene la plantilla básica de la construcción I, como se ejemplifica en (65), es decir, el sujeto agente (la primera persona del singular), el dativo benefactivo (les, cuyo referente es mis jefes) y el objeto directo tipo paciente (todo); sin embargo, el verbo tener incorpora la predicación secundaria bien limpiecito, lo cual da lugar a un nuevo tipo de construcción.

La construcción V difiere de las anteriores en que engloba los casos con dativo benefactivo que aparecen con verbos de cambio de locación. Este tipo de verbos exige semánticamente tres participantes - un agente, un tema y una locación-, de tal manera que si se añade un dativo benefactivo se obtienen construcciones de cuatro participantes. Así se observa en (66) con el verbo echar, que incluye un sujeto agente (la primera persona del sigular), un dativo benefactivo (te), un objeto directo tipo tema (tus condones) y un objeto prepositivo con la función semántica de locación (en tu mochila). 
La construcción VI se separa de las anteriores al englobar las expresiones con dativos benefactivos que aparecen con verbos que únicamente exigen un participante como trabajar, ejemplificado en (67), que incluye un sujeto agente (la primera persona del singular) y un dativo benefactivo (le).

Por último, la construcción VII difiere de las anteriores en que no codifica sintácticamente al agente. En efecto, se trata de una construcción impersonal que incluye, como se observa en (68), el clítico se, un sujeto tipo paciente (una despedida de casada) y un benefactivo (le). El clítico se permite que el agente quede relegado de la construcción y, al mismo tiempo, que el paciente sea promovido a la función sintáctica de sujeto. La construcción VII, si bien es menos agentiva que las anteriores, no es eventiva, dado que no denota un evento espontáneo o accidental, sino que se interpreta que es un agente (implicado conceptual y semánticamente, pero no expresado ni léxica ni sintácticamente) el que desencadena la afectación.

Veamos ahora el número de casos con los que cuenta cada una de las siete construcciones agentivas:

\section{TABLA 4}

Frecuencias de los tipos de construcciones agentivas

\begin{tabular}{|c|c|c|}
\hline CONSTRUCCIONES AGENTIVAS & CASOS & PORCENTAJE \\
\hline I. $\left[S(A g)+C l_{i}+V+O D(P t e / T e m a)+\operatorname{Dat}(\text { Ben })_{i}\right]$ & 624 & $79.7 \%$ \\
\hline II. $\left[S(A g)+C l_{i}+V+\varnothing(\right.$ Pte $)+$ Dat $\left.(\text { Ben })_{i}\right]$ & 46 & $5.87 \%$ \\
\hline III. $\left[\mathrm{S}(\mathrm{Ag})+\mathrm{Cl}_{i}+\mathrm{V}+\mathrm{FP}(\right.$ de comer $)+$ Dat $\left.(\text { Ben })_{i}\right]$ & 12 & $1.53 \%$ \\
\hline IV. $\left[S(A g)+C_{i}+V+\text { Pred. Sec. + OD (Pte) + Dat (Ben) }\right)_{i}$ & 3 & $0.38 \%$ \\
\hline V. $\left[S(A g)+C l_{i}+V+O D(T e m a)+O P(\right.$ Loc $)+$ Dat $\left.(\text { Ben })_{i}\right]$ & 69 & $8.82 \%$ \\
\hline VI. $\left[S(A g)+C l_{i}+V+\operatorname{Dat}(B e n)_{i}\right]$ & 13 & $1.66 \%$ \\
\hline \multirow[t]{2}{*}{ VII. $\left[\right.$ sepas $+C l_{i}+V+S($ Pte $)+$ Dat $\left.(\text { Ben })_{i}\right]$} & 16 & 2.04 \\
\hline & 783 & $100 \%$ \\
\hline
\end{tabular}

La tabla 4 muestra que la construcción I de tres participantes, que constituye el modelo prototípico, es la más frecuente con 624 casos, lo que equivale al 79.7\%. Prácticamente esta construcción engloba ocho de cada diez ejemplos, lo cual la vuelve la estructura emblemática de las construcciones agentivas.

Ahora bien, es importante señalar que la gran mayoría de estas construcciones agentivas son de benefactivo; a pesar de que se hayan encontrado casos con interpretación adversa 
(me hacía sus berrinches), la afectación tiende a ser ampliamente positiva, como lo muestra la siguiente tabla:

\section{TABLA 5}

Distribución del tipo de afectación en las construcciones agentivas

\begin{tabular}{lccc} 
CONSTRUCCIONES AGENTIVAS & CASOS & PORCENTAJE \\
\hline Con afectación positiva & 648 & $82.76 \%$ \\
\hline Con afectación negativa & 135 & $17.24 \%$ \\
\hline & Total & $\mathbf{7 8 3}$ & $\mathbf{1 0 0 \%}$ \\
\hline & & &
\end{tabular}

En efecto, la tabla 5 indica que las construcciones agentivas tienden a tener una afectación positiva, así ocurre con el $82.76 \%$ de los casos, mientras que la afectación negativa aparece con poca frecuencia, solo en el $\mathbf{1 7 . 2 4 \%}$ de los ejemplos. Con base en esta tendencia, proponemos el término construcciones agentivas benefactivas, el cual, por un lado, deja ver que existe una fuerte correlación entre las construcciones agentivas y la afectación positiva, y, por otro, permite sugerir la subcategoría de dativo benefactivo, entendida como un tipo de dativo de afectación cuyo referente experimenta típicamente un beneficio.

\subsection{Clasificaciones semánticas de los benefactivos}

En la sección anterior, sugerimos el término dativo benefactivo para el dativo de afectación de las construcciones agentivas. En esta, nos concentraremos en definir los tipos de benefactivos que existen en español, de acuerdo con la relación que estos establecen con el tema o el paciente y con base en las paráfrasis que representan mejor su sentido.

Después de analizar las características semánticas y el comportamiento sintáctico de los dativos en las construcciones agentivas del corpus y con base en las clasificaciones propuestas por Van Valin y LaPolla (1997) y Song (2010), definimos cuatro tipos de benefactivos en español: i) el receptor potencial, ii) el poseedor, iii) el deputativo y iv) el pleno. El primero es el más común y se da, en nuestro corpus, principalmente con verbos del tipo hacer y comprar:

(69) a. yo hago de todo/ les hago una comida/ otra y otra [a mis hijos] (CSCM)

b. "papá cómprame unas papas" (CSCM)

En los ejemplos anteriores, el benefactivo es potencialmente un receptor: de una comida en (69a) y de unas papas en (69b). Nótese que el referente del dativo no es poseedor del tema; más bien, es esperable que se vuelva poseedor. 
En contraste, el benefactivo poseedor se ve afectado positivamente porque algo que le pertenece es susceptible de sufrir un cambio de estado, así se advierte en los ejemplos de (70):

(70) a. Iuego otro señor quiere que le pinte su departamento (CSCM)

b. me mandó Ilamar una señora que le barnizara un comedorcito (CSCM)

En algunas ocasiones, la relación de posesión se hace más evidente porque se incluye una frase nominal poseída como en (70a) — su departamento - ; en otras, la frase nominal no incluye un adjetivo posesivo como en (70b) - un comedorcito - ; sin embargo, el contexto permite determinar que la entidad se encuentra en el dominio de posesión del beneficiario. Es evidente, pues, que la relación posesiva detona la afectación en estos casos.

Por su parte, el benefactivo deputativo obtiene un beneficio a partir de que alguien realiza algo que le corresponde hacer a él, como se observa en las expresiones de (71):

(71)a. aquí era obligación que hiciera tareas/ allá su papá le hacía la tarea [a la hija] (CSCM)

b. y verá usted que va usted a encontrar a su-/ a sus padres"/ bueno/ pues ¿qué cree usted?/ que sí/ ella me escribió la carta/ [la informante es analfabeta y su comadre le escribe una carta para que encuentra a sus padres] (CSCM)

En los ejemplos anteriores el beneficio se alcanza porque un agente realiza una acción que en principio atañe solo al beneficiario, así ocurre en actividades como hacer la tarea y escribir una carta. En otras palabras, la afectación positiva se consigue gracias a que "alguien hace algo en lugar del beneficiario".

Finalmente, el beneficiario pleno se extiende a predicados sin entidades creadas, modificadas o desplazadas, que cuentan con un agente que al ejecutar una acción desencadena un beneficio en otro participante, así lo muestra el ejemplo de (72):

(72) pero pues < pus> ya me conocen/ ya saben cómo soy/ pero como ya le digo a < a:>/ ¡A!/ que es el < el:> el encargado/ ¿no?/ le digo/ "pues < pus> mientras yo te trabaje/ pues < pus> no hay problema" (CSCM)

En efecto, construcciones como la de (72) no tienen un poseedor o un receptor potencial; más bien, la única relación que es posible identificar entre el trabajador y el patrón es la de benefacción pura.

Estas clasificaciones semánticas se relacionan también con distintos comportamientos sintácticos. Efectivamente, el beneficiario receptor potencial, que se observa en las construc- 
ciones de (73), puede sustituirse por un complemento prepositivo introducido por para, como se advierte en (74):

(73) a. Juan le compró un pastel a María

b. Juan le hizo un dibujo a María

(74) a. Juan compró un pastel para María

b. Juan hizo un dibujo para María

Por su parte, la mejor paráfrasis del beneficiario poseedor, ejemplificado en (75), se consigue al sustituirlo por un complemento adnominal introducido por la preposición de -así se observa en (76) - y no por una frase prepositiva encabezada por para, que, si bien no genera expresiones agramaticales — como se muestra en (77)—, sí pierde el matiz semántico de posesión implícito en los ejemplos de (75) y (76).

(75) a. Juan le pintó el departamento a Pedro

b. Juan le lavó el carro a Pedro

(76) a. Juan pintó el departamento de Pedro

b. Juan lavo el carro de Pedro

(77) a. ?Juan pintó el departamento para Pedro

b. ?Juan lavo el carro para Pedro

Con respecto al beneficiario deputativo, ilustrado en (78), la frase en lugar de... resulta sumamente adecuada para reproducir el mismo sentido, tal como lo muestran los ejemplos de (79):

(78) a. Juan le hizo la tesis a Pedro

b. Juan le escribió una carta a Pedro

(79) a. Juan hizo la tesis en lugar de Pedro

b. Juan escribió una carta en lugar de Pedro

Finalmente, aunque el beneficiario pleno de algunos casos como el de (80) puede parafrasearse con para, como se observa en (81), el hecho de que no cuente con un OD indica que no puede considerarse un receptor potencial; por lo tanto, se sugiere una sustitución mucho más neutral como la de (82): en beneficio de.

(80) Juan le trabaja a María

(81) Juan trabaja para María 
(82) Juan trabaja en beneficio de María

La siguiente tabla muestra cómo se distribuyen los benefactivos en las 783 expresiones con estructuras agentivas localizadas en el corpus:

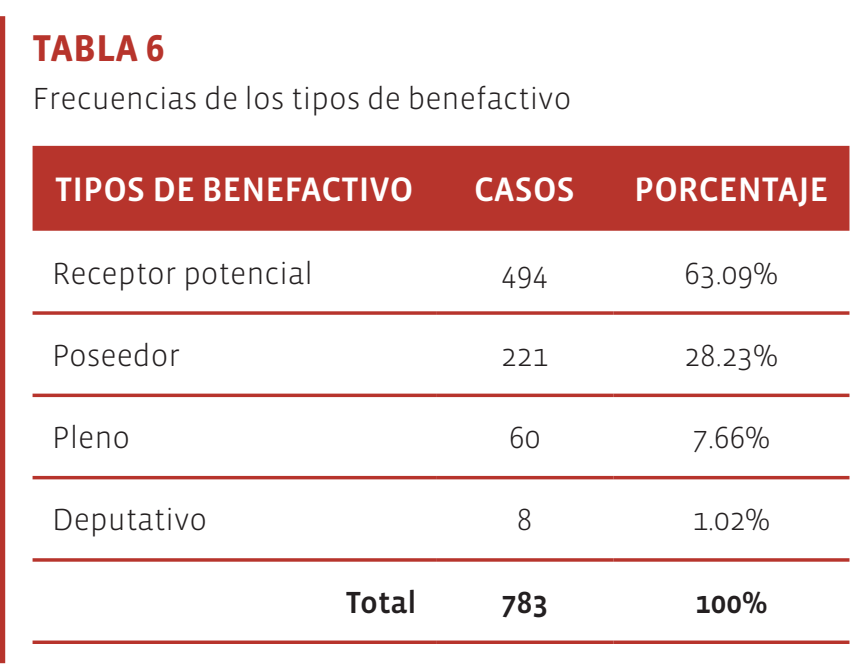

La tabla 6 permite ver que los benefactivos más frecuentes son el receptor potencial y el poseedor, los cuales cubren el $63.09 \%$ de las ocurrencias y el $28.23 \%$, respectivamente. Estas frecuencias sugieren que los benefactivos se encuentran relacionados semánticamente a los receptores, por un lado, y a los poseedores, por otro. Lo primero se advierte en la aproximación cognitiva (Newman, 1996; Shibatani, 1996; Maldonado, 2000 y 2002; entre otros), que considera que las construcciones de benefactivo toman como modelo el esquema semántico-sintáctico del verbo dar, el cual, por supuesto, codifica al receptor como dativo. Lo segundo también ha sido señalado por varios autores (Shibatani, 1996; Van Valin y LaPolla, 1997; Maldonado, 2002; Song, 2010; Kittilä y Zúliga, 2010; entre otros) que coinciden en que existe una relación de posesión entre el benefactivo y el paciente.

Ahora bien, a pesar de que entre los benefactivos el receptor potencial y el poseedor sean los más frecuentes, vale destacar que se identificaron 60 casos con un benefactivo pleno. En otras palabras, los ejemplos de benefacción pura, en los cuales no hay un tema o un paciente que puede asociarse a la noción de recepción o a la de posesión, para nada son marginales; por el contrario, tienen una frecuencia considerable, sobre todo si se advierte el hecho de que estos casos tienen una estructura sintáctica S-DAT, que los aleja totalmente del esquema semántico-sintáctico de tres participantes que representa el modelo construccional de dar. En pocas palabras, la importancia de los benefactivos plenos radica en que plantean que la benefacción puede estar asociada a otros esquemas semántico-sintácticos. 


\section{Construcciones eventivas malefactivas}

\subsection{Tipos de construcciones eventivas}

Las construcciones eventivas se distribuyen en cinco subtipos. A continuación, enumeramos y ejemplificamos cada uno de ellos con el desglose de sus funciones sintácticas y semánticas:

I. $\quad\left[S(\right.$ Pte $)+s e+\mathrm{Cl}_{\mathrm{i}}+\mathrm{V}+$ Dat $\left.(\mathrm{Mal})_{\mathrm{i}}\right]$

(83) se te descompuso el lavabo (CSCM)

II. $\quad\left[\mathrm{S}(\right.$ Pte $)+$ se $+\mathrm{Cl}_{i}+\mathrm{V}+\mathrm{OP}($ Causa $)+$ Dat $\left.(\text { Mal })_{i}\right]$

(84) se me enfermó de varicela (CSCM)

III. $\quad\left[S(\right.$ Pte $)+s e+\mathrm{Cl}_{i}+\mathrm{V}+$ Atributo + Dat $\left.(\text { Mal })_{i}\right]$

(85) no hay desnutridos/ aunque después se les pusieron las cosas horribles [a los cubanos]/ hace como diez años (CSCM)

IV. $\quad\left[S(\right.$ Causa $)+C l_{i}+V+O D($ Pte $)+$ Dat $\left.(\text { Mal })_{i}\right]$

(86) el viento le voló sus calzones/ sus camisa y todo (CSCM)

V. $\quad\left[S(\right.$ Pte $)+C l_{i}+V+$ Dat $\left.(\text { Mal })_{i}\right]$

(87) ustedes recogen generalmente flores silvestres para ver si les pegan (CSCM)

El ejemplo (83) permite ver que la construcción I cuenta con un clítico se, un dativo malefactivo (te), un verbo de cambio de estado (descomponer) y un S (Pte) (el lavabo). Se trata de un evento de tipo espontáneo o accidental en el que no interviene ningún agente.

La construcción II, ejemplificada en (84), es similar a la de I pero se separa de ella en que incluye un OP tipo causa (de varicela), que indica lo que provocó la enfermedad.

La construcción III, ilustrada en (85), cuenta con un verbo seudocopulativo (ponerse), un atributo (horribles), un S (Pte) (Ias cosas) y un dativo malefactivo (les). En este caso tampoco interviene un agente.

La construcción IV incluye tres participantes, así se observa en (86): una causa codificada en función de S (el viento), un paciente en función de OD (sus calzones, sus camisas y todo) y un malefactivo codificado en dativo (le). Se trata de una construcción eventiva, es decir, no agentiva, puesto que el viento no cumple con las características del agente, a saber, el constituir una entidad animada con voluntad; la construcción, pues, no implica el propósito de generar una afectación específica.

Por último, la construcción V engloba los casos con dativos de afectación que aparecen con verbos intransitivos como pegar en la acepción de 'florecer', que, en el ejemplo (87), hace referencia a que las plantas se recogen para que después de ser plantadas logren crecer. En 
esta expresión, las flores silvestres funcionan como un S (Pte), y el pronombre de dativo les, como un malefactivo.

A continuación se presenta una tabla que indica con qué frecuencia aparecieron en el corpus cada una de estas cinco construcciones:

\section{TABLA 7}

Frecuencias de los tipos de construcciones eventivas

\begin{tabular}{|c|c|c|}
\hline CONSTRUCCIONES EVENTIVAS & CASOS & PORCENTAJE \\
\hline I. $\left.\left[S(\text { Pte })+s e+\mathrm{Cl}_{i}+\mathrm{V}+\operatorname{Dat}(\mathrm{Mal})\right)_{i}\right]$ & 85 & $90.43 \%$ \\
\hline II. $\left[S(\right.$ Pte $)+s e+\mathrm{Cl}_{i}+$ V + OP (Causa) + Dat (Mal) $\left.)\right]$ & 1 & $1.06 \%$ \\
\hline III. [S (Pte) + se $+\mathrm{Cl}_{i}+\mathrm{V}+$ Atributo + Dat $\left.(\text { Mal) })_{i}\right]$ & 3 & $3.19 \%$ \\
\hline IV. [S (Causa) + Cl $l_{i}+V+$ OD (Pte) + Dat (Mal) $\left.)\right]$ & 4 & $4.2 \%$ \\
\hline V. $\left[S(\right.$ Pte $\left.)+\mathrm{Cl}_{i}+\mathrm{V}+\operatorname{Dat}(\mathrm{Mal})_{i}\right]$ & 1 & $1.06 \%$ \\
\hline Total & 94 & $100 \%$ \\
\hline
\end{tabular}

La tabla 7 indica que, de los 94 casos totales, 85, es decir el 90.43\%, corresponden a la construcción I, lo que la convierte en la construcción eventiva básica. Las otras cuentan con pocas ocurrencias; sin embargo, muestran que los malefactivos también tienen la posibilidad de aparecer en distintas configuraciones sintáctico-semánticas.

Nótese que Ilamamos malefactivas a las construcciones eventivas, porque se inclinan categóricamente por la afectación negativa, así lo indica la siguiente tabla:

\section{TABLA 8}

Distribución de la afectación en las construcciones eventivas

\begin{tabular}{|c|c|c|c|}
\hline CONSTRUCCIONES EVENTIVAS & & CASOS & PORCENTAJE \\
\hline Con afectación negativa & & 93 & $98.94 \%$ \\
\hline Con afectación positiva & & 1 & $1.06 \%$ \\
\hline & Total & 94 & $100 \%$ \\
\hline
\end{tabular}

Efectivamente, solo hay un caso con afectación positiva; se trata del ejemplo (87), que se mencionó anteriormente (ustedes recogen generalmente flores silvestres para ver si les pegan); en los 93 casos restantes, el 98.94\%, el referente del dativo sufre una afectación negativa. Así 
pues, a pesar de que en la bibliografía no se hable de malefactivos en español, esta inclinación muestra que es pertinente establecer esta subcategoría, por supuesto siempre asociada a las construcciones eventivas.

\subsection{Clasificaciones semánticas de los malefactivos}

Los malefactivos se pueden clasificar en dos clases con base en la relación que establecen con el paciente: Ios posesivos y los emotivos. Los primeros manifiestan una relación de posesión alienable con una entidad inanimada; los segundos, un vínculo emocional con una entidad animada. Ambos se ejemplifican en (88) y (89), respectivamente:

(88) a. el pantalón se me mojó (CSCM)

b. regalé mis dulces que se me caducaron (CSCM)

(89) a. Ilegó una enfermedad y se me enfermaron [mis pollitos] (CSCM)

b. se le murió su hijo ahí en el hospital (CSCM)

En los ejemplos de (88) se observa que el malefactivo es poseedor del pantalón, en (88a), y de los dulces, en (88b). En contraste, en las expresiones de (89), el malefactivo, más que una relación posesiva, manifiesta una relación emotiva con los pollitos, en (89a), y el hijo en (89b).

La siguiente tabla indica con qué frecuencia aparecen estos tipos de malefactivos:

\section{TABLA 9}

Frecuencia de los tipos de malefactivos

\begin{tabular}{|c|c|c|}
\hline MALEFACTIVOS & CASOS & PORCENTAJE \\
\hline Posesivos & 51 & $54.26 \%$ \\
\hline Emotivos & 43 & $45.74 \%$ \\
\hline Total & 94 & $100 \%$ \\
\hline
\end{tabular}

La tabla 9 permite ver que los malefactivos posesivos son ligeramente más frecuentes que los emotivos, puesto que con 51 casos cubren el 54.36\% de las ocurrencias. Así pues, la posesión resulta no solo un rasgo asociado al beneficio, como se indicó en el apartado (3.2), sino que también se encuentra relacionado con el perjuicio.

Vale destacar que no se identificaron ni receptores potenciales ni deputativos en las construcciones eventivas, lo cual separa al malefactivo del dativo benefactivo. De igual for- 
ma, el primero se distingue del segundo en que aparece frecuentemente involucrado en rela-

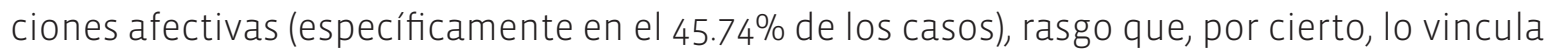
con el dativo ético.

Hemos visto, pues, a lo largo de la sección (4) que los eventos de tipo espontáneo o accidentales están estrechamente relacionados con los malefactivos, lo cual, a pesar de que es un hecho que ya ha sido identificado por Smith (2005), requiere mayor atención, puesto que translingüísticamente la atención se ha centrado en los benefactivos y en las construcciones agentivas y poco se ha dicho de los malefactivos y de las construcciones no agentivas en diferentes lenguas. En este marco, ha sido especialmente revelador atender las construcciones eventivas del español, puesto que, si bien algunas de ellas han sido consideradas en el estudio de Melis y Flores (2012) como construcciones de tipo se me, no se había reparado en el hecho de que categóricamente tienen un efecto adverso, lo cual sí se pone de relieve en este estudio.

\section{Conclusiones}

En este estudio se abordaron cuatro temas: i) la codificación de los benefactivos y malefactivos translingüísticamente, ii) la delimitación del dativo de afectación, iii) las construcciones agentivas benefactivas y iv) las construcciones eventivas malefactivas.

En cuanto al primer tema, con base en el estudio de Radetzky y Smith (2010), mostramos, por un lado, ejemplos de lenguas que colapsan la afectación positiva y negativa en una misma construcción morfosintáctica y, por otro lado, destacamos la existencia de lenguas que cuentan con mecanismos morfosintácticos para diferenciar el efecto benéfico del efecto adverso.

Con respecto al segundo tema, esbozamos un panorama de los dativos no regidos, que distingue tres categorías: i) el dativo parte-todo, ii) el dativo de afectación y iii) el dativo ético. Además, mostramos que el dativo de afectación se distribuye en dos macroestructuras: la agentiva $-\mathrm{S}(\mathrm{Ag})+\mathrm{Cl}_{i}+\mathrm{V}+\mathrm{OD}(\mathrm{Pte} / \mathrm{Tema})+$ Dat $(\text { Ben })_{i}-\mathrm{y}$ la eventiva $-\mathrm{S}(\mathrm{Pte})+\mathrm{se}+\mathrm{Cl}+\mathrm{V}+$ Dat $(\mathrm{Mal})_{i}-$. Para la primera identificamos siete variaciones construccionales; para la segunda, cinco.

En lo que concierne a la semántica de las construcciones, distinguimos dos tipos: Ias agentivas benefactivas y las eventivas malefactivas; mediante estos nombres destacamos que son las construcciones, y no el pronombre, las que determinan el efecto benéfico o adverso, puesto que la eventiva selecciona verbos con significados cargados hacia lo negativo, y la agentiva, verbos con significados de tendencia positiva; además, demostramos que cada una de ellas por sí sola realza un tipo de afectación, en tanto que con verbos de semántica más neutral el efecto se actualiza en función de la construcción.

En cuanto a las construcciones agentivas benefactivas, advertimos que, a pesar de neutralizar la afectación, tienden a manifiestar un efecto positivo que naturalmente se extiende 
hasta el pronombre de dativo; por ello, sugerimos llamar benefactivo al dativo de afectación de estas construcciones. Asimismo, con base en criterios semánticos y sintácticos se identificaron cuatro tipos de benefactivos: el receptor potencial, el poseedor, el pleno y el deputativo.

Con respecto a las construcciones eventivas malefactivas, mediante el análisis del corpus, revelamos que están especializadas en expresar un efecto adverso que recae en el pronombre de dativo; por consiguiente, es pertinente hablar del dativo malefactivo en español como una subcategoría del dativo de afectación asociada a construcciones no agentivas. Además, otro aspecto que valida la existencia de malefactivos es que, en contraste con el benefactivo, solo cuenta con dos subtipos: el posesivo y el emotivo.

De todo lo anterior se desprende nuestra propuesta central: el español sí cuenta con un mecanismo gramatical para distinguir la afectación negativa de la positiva, a saber, la macroestructura [S (Pte) $+\mathrm{se}+\mathrm{Cl}_{i}+\mathrm{V}+$ Dat $\left.(\mathrm{Mal})_{i}\right]$, especializada en el efecto adverso. En este sentido, tipológicamente el español se puede ubicar, al menos parcialmente, junto con las lenguas que cuentan con un recurso gramatical diferenciador, en este caso, un recurso construccional.

\section{Bibliografía citada}

Abdel-Hafiz, Ahmed, 1988: A reference grammar of Kunuz Nubian. Tesis de doctorado, Universidad de Nueva York en Búfalo.

Alarcos, Emilio, 1994: Gramática de la lengua española, Madrid: Espasa.

Alcina, Juan, y José M. BlecuA, 1975: Gramática española, Barcelona: Ariel.

Bello, Andrés, 1988 [1847]: Gramática de la lengua castellana destinada al uso de los americanos, Madrid: Arco Libros.

BecerRa, Silvia, 2007: Estudio diacrónico y sincrónico del objeto indirecto en el español peninsular y de América, Copenhague: Museum Tusculanum Press.

Boneh, Nora, y Léa Nash, 2013: "Core and Noncore Datives in French" en Beatriz Fernández y Ricardo ETxePARE (eds.): Variation in Datives: A Microcomparative perspective, Oxford: Oxford University Press, 22-49.

Cano, Rafael, 1981: Estructuras sintácticas transitivas del español actual, Madrid: Gredos.

Chung, Taegoo, 1993: "The Affected Construction in Korean and Japanese”, Japanese/Korean Linguistics 24, 1025-1052.

Cifuentes, José, y Jesús Llopis, 1996: Complemento indirecto y complemento de lugar: estructuras locales de base personal en español, Alicante: Universidad de Alicante. 
Company, Concepción, 2006: "El objeto indirecto" en Concepción Company (dir.): Sintaxis histórica de la lengua española. Primera parte: La frase verbal, México: Fondo de Cultura Económica Universidad Nacional Autónoma de México, 479-574.

Contl, Carmen, 2008: Receptores y beneficiarios. Estudio tipológico de la ditransitividad, Munich: Lincom Europa.

Contı, Carmen, 2011: "Possessive Dative Revisited: Another View of External Possession in Spanish”, Studia Linguistica 65 (2), 170-197.

Delbecque, Nicole, 1992: "El dativo español: una tipología” en Juan Villegas (ed.): Actas del XI Congreso de la Asociación Internacional de Hispanistas, Irvine: Universidad de California, 124-138.

Delbecque, Nicole, y Béatrice Lamiroy, 1996: "Towards a Tipology of the Spanish Dative" en WiIliam Van Belle y Willy Van Langendonck (eds.): The Dative. Volume 1: Descriptive Studies, Amsterdam/Philadelphia: John Benjamins, 73-117.

Demonte, Violeta, 1994a: "Datives in Spanish", University of Venice Working Papers in Linguistics 4 (1), 71-96.

Demonte, Violeta, 1994b: "La Ditransitividad en Español: Léxico y Sintaxis" en Violeta Demonte (ed.): Gramática del Español, México: Colegio de México, 431-470.

Demonte, Violeta, 1995: "Dative alternation in Spanish”, Probus 7, 5-30.

Dı Tulııo, Ángela, 1998: Manual de gramática del español. Desarrollos teóricos. Ejercicios. Soluciones, Buenos Aires: Edicial.

Dı Tullıo, Ángela, y Marisa Malcuorı, 2012: Gramática del español para maestros y profesores del Uruguay, Uruguay: ANEP.

Dıк, Simon, 1980: The Theory of Functional Grammar. Part I: The Structure of the Clause, Dordrecht: Foris Publications.

DIk, Simon, 1989: The Theory of Functional Grammar. Part II: Complex and Derived Constructions, Berlin: Mouton de Gruyter.

Fernández, Salvador, 1987 [1951]: Gramática española. 3.2. El pronombre, Madrid: Arco Libros.

GILI, Samuel, 1979 [1948]: Curso superior de sintaxis española, décimo segunda edición, BarceIona: Vox-Bibliograf.

GoldberG, Adele, 1995: Constructions: A Construction Grammar Approach to Argument Structure, Chicago: University of Chicago Press.

GutiérreZ, Salvador, 1977: "Sobre los dativos superfluos”, Archivum XXVII-XXVIII, 415-452. 
Gutiérrez, Salvador, 1999: "Los dativos" en Ignacio Bosque y Violeta Demonte (dirs.): Gramática descriptiva de la lengua española, Madrid: Espasa, 1855-1930.

Hernanz, M. Lluïsa, y José Ma. Brucart, 1987: La sintaxis. I. Principios generales. La oración simple, Barcelona: Crítica.

IBÃNEz, Sergio, 2003: "Introduciendo participantes en la Estructura Argumental: el caso del aplicativo “le' del español” en Víctor M. Sánchez (ed.): Actas del XIII Congreso Internacional, Costa Rica: Asociación de Lingüística y Filología de América Latina/Universidad de Costa Rica, 1125-1132.

IBÃNez, Sergio, 2004: Estructuras verbales de dos objetos. Hacia una redefinición semánticosintáctica del fenómeno. El caso de los verbos de "poner" y de "quitar". Tesis de doctorado, Universidad Nacional Autónoma de México.

Ibẫez, Sergio, 2006: “El papel del clítico 'le’ en las construcciones de duplicación de dativo. Evidencia diacrónica” en Concepción Company y José G. Moreno (eds.): Actas del VII Congreso Internacional de Historia de la Lengua Española, Mérida (Yucatán): Arco Libros y Asociación de Historia de la Lengua Española, 719-730.

JAndA, Laura, 1993: A Geography of Case Semantics. The Czech Dative and the Russian Instrumental, Berlín: Mouton de Gruyter.

Jenny, Mathias, 2010: "Benefactive strategies in Thai" en Fernando ZúñIGa y Seppo KITtILÄ (eds.): Benefactives and Malefactives. Typological perspectives and case studies, Amsterdam/Philadelphia: John Benjamins, 377-392.

KITTILÄ, Seppo, y Fernando ZúNIIGA, 2010: "Introduction. Benefaction and malefaction from a crosslinguistic perspective" en Fernando ZúNíIga y Seppo KıтTILÄ (eds.): Benefactives and Malefactives. Typological perspectives and case studies, Amsterdam/Philadelphia: John Benjamins, 1-28.

LaRA, Luis (dir.), 2010: Diccionario del Español de México, México: Colegio de México.

LeE, Chung-Min, 1974: Abstract Syntax and Korean with Reference to English, Seúl: Pan Korea Book Corp.

LORD, Carol, Foong YaP y Schoichi IWASAKI, 2002: "Grammaticalization of 'give': African and Asian perspectives” en Ilse Wischer y Gabriele DIEWALD (eds.): New Reflections on Grammaticalization, Amsterdam/Philadelphia: John Benjamins, 217-235.

Maldonado, Ricardo, 1994: "Dativos de interés sin intereses" en Annett Endruschat, Mário Vilela and Gerd Wotjak (eds.): Verbo e estructuras frásicas. Actas do IV Coloquio Internacional de Linguística Hispánica, Porto: Facultade de Letras do Porto, 241-264.

Maldonado, Ricardo, 2000: "Tanto para nada: trayectorias conceptuales en construcciones benefactivas y finales" en Ricardo Maldonado (ed.): Estudios Cognoscitivos del Español, Castelló: Asociación Española de Lingüística Aplicada / Universidad Autónoma de Querétaro, 111-130. 
Maldonado, Ricardo, 2002: "Objective and subjective datives" en Arie Verhagen (ed.): Cognitive Linguistics 13 (1), Berlín / Nueva York: Mouton de Gruyter, 1-65.

Martín, Alonso, 1974: Gramática del español contemporáneo, Madrid: Guadarrama.

Martín, Pedro, y Yolanda Lastra (coords.), 2011-2015: Corpus sociolingüístico de la ciudad de México, México: El Colegio de México.

Masullo, Pascual, 1992: Incorporation and Case Theory in Spanish. A Crosslinguistic Perspective. Tesis doctoral. Washington: University of Washington.

Melis, Chantal, y Marcela Flores, 2007: "Los verbos seudo-impersonales del español. Una caracterización semántico-sintáctica”, Verba. Anuario Galego de Filología 34, 7-57.

Melis, Chantal, y Marcela Flores, 2012: "Emergence and grammaticalization of constructions within the se me network of Spanish" en Kristin Davidse y otros (eds.): Grammaticalization and Language Change. New reflections, Amsterdam: John. Benjamins, 249-270.

Newman, John, 1996: Give. A Cognitive Linguistic Study, Berlín / Nueva York: Mouton de Gruyter.

Ortiz, Rosa, 2006: "La bitransitividad” en Concepción Company (dir.): Sintaxis histórica de la lengua española. Primera parte: La frase verbal, México: Fondo de Cultura Económica-Universidad Nacional Autónoma de México, 575-670.

PORTo, José-Álvaro, 1992: Complementos argumentales del verbo: directo, indirecto, suplemento y agente, Madrid: Arco Libros.

Radetzky, Paula, y Tomoko Smith, 2010: "An areal and cross-linguistic study of benefactive and malefactive constructions" en Fernando ZúÑIGa y Seppo KITTILÄ (eds.): Benefactives and Malefactives. Typological perspectives and case studies, Amsterdam/Philadelphia: John Benjamins, 97-120.

Real Academia Española (RAE), 1973: Esbozo de una nueva gramática de la lengua española, Madrid: Espasa/Calpe.

RAE y Asociación de Academias de la lengua Española (ASALE), 2009: "El complemento indirecto" en Nueva gramática de la lengua española, Madrid: Espasa, 2655-2714.

Romero, Juan, 2008: Los dativos en el español, Madrid: Arco Libros.

Seco, Rafael, 1989 [1930]: Manual de gramática española, revisado y ampliado por Manuel Seco, undécima edición, Buenos Aires: Aguilar.

Shibatani, Masayoshi, 1996: "Applicatives and Benefactives: A Cognitive Account" en Masayoshi ShibatAni y Sandra Thompson (eds.): Grammatical Constructions: Their Form and Meaning, Oxford: Oxford University Press, 157-194. 
Smith, Tomoko, 2005: Affectedness Constructions: How Languages Indicate Positive and Negative Events. Tesis doctoral, Universidad de California en Berkeley.

Sмiтн, Tomoko, 2010: "Cross-linguistic categorization of benefactives by event structure. A preliminary framework for benefactive typology" en Fernando ZÚÑIGA y Seppo KITTILÄ (eds.): Benefactives and Malefactives. Typological perspectives and case studies, Amsterdam/Philadelphia: John Benjamins, 71-95.

Song, Jae 2010: "Korean benefactive particles and their meanings" en Fernando Zúñiga y Seppo KITTILÄ (eds.): Benefactives and Malefactives. Typological perspectives and case studies, Amsterdam/Philadelphia: John Benjamins, 393-418.

Tsubol, Eijiro, 2010: "Malefactivity in Japanese" en Fernando ZúñIGa y Seppo KıtTILÄ(eds.): Benefactives and Malefactives. Typological perspectives and case studies, Amsterdam/Philadelphia: John Benjamins, 419-435.

Van Hoecke, Willy, 1996: "The Latin Dative" en William van Belle y Willy van Langendonck (eds.): The Dative. Volume 1: Descriptive Studies, Amsterdam/Philadelphia: John Benjamins, 3-37.

Van Valin, Robert, y Randy LAPolla, 1997: Syntax: Structure, Meaning, and Function, Cambridge: Cambridge University Press.

VÁzquez, Victoria, 1995: El complemento indirecto en español, Santiago de Compostela: Universidade de Santiago de Compostela. 